\title{
Uzman hekim yetkinliklerinin ölçeklenmesi ve karşılaştırılması
}

\section{Scaling and comparing the competencies of a medical expert}

\author{
Nezaket Bilge Uzun, ${ }^{1}$ Melih Elçin² \\ ${ }^{1}$ Mersin Üniversitesi Yenişehir Yerleşkesi Eğitim Fakültesi Mersin. Turkey \\ ${ }^{2}$ Hacettepe Üniversitesi Tıp Fakültesi. Ankara. Turkey
}

\section{Özet}

Amaç: Bu araştırmada. uzman hekimde bulunması istenilen yetkinliklerin ikili karşılaştırma ile ölçeklemesi ve bu yetkinliklerin uzmanlığını almış hekim ve tıp fakültesi öğrencileri bakımından daha anlamlı bir ölçek üzerinde karşılaştırılması amaçlanmıştır.: Tıp Eğitimi Akreditasyon Konseyi mesleki yetkinlikleri; Hasta bakımı. Tıbbi bilgi. Uygulamaya dayalı öğrenme ve gelişim. Kişiler arası iletişim becerileri. Profesyonellik. Sistemlere dayalı uygulama biçiminde bildirmiştir.

Gereç ve Yöntem: Ölçekleme; denek ve yargıcı tepkilerinden elde edilen verilerin istatistiksel işlemler yoluyla daha anlamlı ve nitelikli verilere dönüştürülmesini sağlar ve verilerin yorumlanmasını kolaylaştıırı. Araştırma. Hacettepe Üniversitesi tıp fakültesinde çalışmakta olan 34 uzman hekim ve 47 klinik eğitimine devam eden dönem IV öğrencileri ile yapılmıştır.

Bulgular: İkili karşılaştırmalar yöntemi ile yapılan ölçekleme çalışmasından elde edilen bulgulara göre. uzman hekimler de bulunması gereken yetkinliklerin hesaplanan ölçek değerlerinin en büyük olan yetkinlikten en küçük değere sahip olan yetkinliğe göre sıralandığında en büyük değere sahip olan yetkinliğin uzmanlığını alan hekimler için tıbbi bakım becerisi; tıp fakültesi öğrencileri içinse uygulamaya dayalı öğrenme ve gelişim olduğu belirlenmiştir.

Sonuç: Uzman hekim yetkinlikleri açısından uzman hekimler ve hekim adayları açısından farklılıklar bulunmaktadır.

Anahtar Sözcükler: İkili karşılaştıma yöntemi; ölçekleme; tıp eğitimi; uzman hekim yetkinlikleri.

$\mathrm{H}$ ekimlik; bilgi. yetenek. sanat. dikkat ve beceri.. vs. isteyen. dinamik bir yapıya ve kritik bir öneme sahip olan. tarihin en eski mesleklerinden biridir. Tıp; "hekimlik mesleği ve ilmi" anlamına gelen Arapça bir kelimedir. Dolayısıyla tıbbın en te-

\begin{abstract}
Introduction: In this study. it was studied what "wanted competencies of a medical expert" should be by scaling study with pairwise comparison to determined. Patient care Medical knowledge Practicebased learning and improvement Interpersonal communication skills Professionalism Systems-based practice were reported as the competencies of The Accreditation Council for Graduate Medical Education (ACGME).

Methods: Scaling; allows the data obtained from subject and judge reactions to be transformed into more meaningful and qualitative data through statistical procedures and facilitates interpretation of data.This research was performed on 34 doctors who works at faculty of medicine in Hacettepe University and 47 medical students.

Results: According to the results of scaling study by pair-wise comparison. when "wanted competencies of a medical expert" was sorted from the most desired competence to the least desired competence by doctors. it was determined that the most desired competence was "Medical knowledge". for students; the most desired competence was Practice-based learning. And the least desired competence was determined as "Patient care" for doctors and "Systems-based practice" for students.
\end{abstract}

Discussion and Conclusion: In terms of competence of specialist physicians there are differences in terms of specialist physicians and medical students.

Keywords: Pair-wise comparison method; scaling; medical education; competencies of a skilled doctor.

mel varlık sebebi hekimler ve hekimlerde bulunan özel bilgi ya da tanımdan hareketle ilimdir. ${ }^{[1]}$ Hekimler. toplum yapısı içinde oldukça güçlü bir meslek olarak kendine yer bulmakla birlikte; Küreselleşme ve bilgi teknolojilerindeki gelişmeler ile birlikte 
toplumun gelişmişlik düzeyi açısından insan gücünün önemli bir faktör haline gelmekte ve her meslek alanında yetkinlikler öne çıkmaktadır. Bu gelişmelerin etkisi hekimlik ve hekim yetkinliklerinin önemi de gün geçtikçe arttırmaktadır.

Yetkinlik; "Belirli bir iş bağlamında bir aktivitenin yapılabilmesi için gerekli olan ve insanların elde edebilecekleri spesifik. belirlenebilir. tanımlanabilir ve ölçülebilir bilgi. yetenek. beceri ve/veya diğer işlerle ilgili karakteristiklerdir ${ }^{[2]}$ YÖK yeterlik çerçevesinde "yetkinlik" kavramı; kazanılmış bilgi ve becerileri. karşılaşılan farklı ve karmaşık durum ve konularda diğer çevresel verilerle birleştirerek ustalıkla etkin bir biçimde kullanabilme yeterliliği olarak tanımlanmaktadır. Bireyin bir mesleğe olan yetkinliği; bireyin mesleğine ilişkin performansın veya davranışın ortaya çıkmasını etkileyerek ortaya konan işin katilesine ve sonuçlarına doğrudan etki eder.

Tıp alanında; uzmanlık alanından bağımsız olarak. hekimden beklenen genel yetkinlikler; Tıp Eğitimi Akreditasyon Konseyi (The Accreditation Council for Graduate Medical Education = ACGME) raporunda şu biçimde sıralanmıștır: ${ }^{[3]}$

- Hasta bakımı (Patient care)

- Tibbi bilgi (Medical knowledge)

- Uygulamaya dayalı öğrenme ve gelişim (Practice-based learning and improvement)

- Kişiler arası iletişim becerileri (Interpersonal communication skills)

- Profesyonellik (Professionalism)

- Sistemlere dayalı uygulama (Systems-based practice)

Benzer biçimde Ulusal Tıp Eğitimi Akreditasyon kurulu da Tıp fakültesi mezunları için yeterlikler çerçevesinde; Tıp fakültesi mezunundan beklenen yeterlikleri; Profesyonel. Sağlık Savunucusu. Ekip üyesi. Danışman. Yönetici-lider. Bilim İnsanı. İletişimci olmak üzere yedi rol üzerinden tanımlamışıır. ${ }^{[4]}$

Yukarıda sıraladığı üzere; hekimler son derece karmaşık bir ortamda faaliyetlerini sürdürmekte iken zaman içerisinde takımlar ve sistemler içerisine daha fazla dahil olmuşlar ve yetkinlik çerçeveleri genişlemiştir. Bu araştırmada ikili karşılaştırmalar yoluyla ölçekleme tekniği ile birleştirilen uzman hekimin yetkinlikleri değerlendirmesi esas alınarak hekimlerin kendi genel yetkinliklerini. buna ilişkin süreçlerini yargılamaları ve değerlendirmeleri hedeflenmiştir.

Sosyal bilimlerde yapılan çalışmalarda; bireylere ve olaylara ilişkin sayısal bilgileri içeren verilerin toplanması. düzenlenmesi. özetlenmesi. analizi ve bu analizler aracılı̆ı̆ıla elde edilen sonuçların yorumlanması ve karar verilmesi alana çok çeşitli katkılar sağlamaktadır. Ortaya konan teorik varsayımların uygulamadaki geçerliliklerinin anlaşılabilmesi için. yapılacak alan araştırmaları ile desteklenmeleri gerekmektedir. Incelenen değişkenlerin ölçek düzeyine uygun analizlerin seçilmesi kritik bir öneme sahip olmakla birlikte. çalışmalarda kullanılan ölçme araçları ile elde edilen verilerin ölçeklenmesi suretiyle bilgi elde edilmeye çalışılır.

Ölçekleme. bir ölçekle toplanan verilerin niteliğini artırdığı gibi aynı zamanda. sadece ölçme aracı geliştirmek değil. basit ölçme sonuçlarını işleyerek standart ölçme aracı geliştirmektir. [5] Ölçekleme işlemi iki yaklaşıma göre yapılır. Bunlar; yargı yaklaşımı ve tepki yaklaşımıdır. Yargı yaklaşımında uzman kanıları dikkate alınarak; tepki yaklaşımında ise denek tepkilerine göre ölçekleme yapılır. Yargı yaklaşımına bağlı olan ölçekleme tekniklerine mutlak yargılama. sıralama. sınıflama ve ikili karşılaştırma teknikleri; tepki yaklaşımına bağlı olan ölçekleme tekniklerine ise. dereceleme toplamları ve çok boyutlu ölçekleme tekniği örnek olarak verilebilir. ${ }^{[5.6]}$

Thurstone'ın ikili karşılaştırmalar tekniği ile yapılan ölçekleme yolu ile aslında sıralı ölçek şeklinde ölçülmüş değişkenler aralıklı ölçek şeklinde değerlendirilebilmekte ve gözlenen değişkenlere ait ölçme sonuçları eşit aralık ölçeğinin özelliklerini taşır hale gelmektedir. ${ }^{[7]}$ Yargıcı yaklaşımını esas alan bu tekniğin önemli avantajlarından biri de basit ve karşılaştırmalı yargıların tümünü kapsamasıdır. ${ }^{[8]}$ Benzer biçimde Titchener (1901) karşılaştırmalı yargılarla ilgili olarak. bireylerin belirli sayıda uyaran verildiğinde. verilen uyaranların hangilerinden daha çok hoşnut oldukları ile ilgili yargılarının kesin olmayacağını. ancak bu uyaranların ikili şekilde verilmesi durumunda daha kesin yargılarda bulunduklarını belirtmiştir. ${ }^{[9]}$

Bu tekniğin tıp eğitiminde bir alanda çalışı masının hem programa fayda sağlayacağı hem de bu yöntemle ilgili az sayıda çalışmaya destek sunacağı düşünülmüştür. Çünkü Tıp eğitiminin amacı. tüm insanların sağlıklı yaşamalarını sağlamak için hekim yetiştirmektir. ${ }^{[10]}$ Bilindiği gibi uzman hekim yetkinliklerinin değerlendirilmesi sağlıkta insan kaynakları uygulamaIarının en temel araştırma konuları arasında yer almaktadır. ${ }^{[1]}$

Bu çalışmada hazırlanan ölçme aracı ile uzman hekimlerin "hekim yetkinliklerini" ikili karşılaştırmalar yolu ile değerlendirmeleri istenmiştir. Bu teknikle hekimden beklenen genel yetkinliklerin ikili karşılaştırma yolu ile ölçeklenerek ölçek niteliğini artırmak. verilerin eşit aralık ölçek özelliği kazanması amaçlanmıştır. Yapılan ikili karşılaştırmalar ile daha ayırt edici bir sıralama yapmanın önemli olduğu düşünülmektedir.

İkili gruplar halinde eşlenerek bu yetkinliklerin karşılaştırılması ve bu biçimde hazırlanmış bir değerlendirme matrisi kullanılması. ortaya çıkabilecek yanlı davranışların önlenmesinde yararlı olduğu düşünülmektedir. Aynı zamanda bu yöntemin eşitliğe ve karar verememeye izin vermemesi de karşılaştırmalardan kesin bir biçimde yararlanmamızı sağlayacaktır. Bu çalışmaya benzer bir çalışma eğitim alanında öğretmenler üzerinde Anıl ve Güler (2006) tarafından yapılmıștır. ${ }^{[12]}$ Yaptıkları araştırmada. nitelikli bir öğretmende bulunması istenilen 8 özelliği ikişerli gruplar hâlinde eşleyerek oluşturdukları ölçeği öğretmen adaylarına uygulamış ve elde ettikleri veriler üzerinden ikili karşılaştırma yöntemi ile ölçeklendirme çalışması yapmışlardır. Çalışmalarının sonuçları incelendiğinde. nitelikli bir öğretmende bulunması istenilen 8 temel özellikten ilkinin meslek sevgisi olduğu belirtilmiştir.

Ülkemizde ölçekleme alanında yapılmış çalışmalar oldukça sınırlı sayıda olmakla birlikte; bu çalışmaların bir kısmının ölçekleme yöntemlerinin karşılaştırılmasını temel aldığı; mes- 
leksel anlamda yapılan ikili karşılaştırmaların genellikle eğitim alanında olduğu görülmektedir. ${ }^{[7.12-17]}$ Daha önce Tıp alanında böyle bir çalışmanın yapılmayışı bu çalışmanın önemli olduğunu düşündürmektedir. Tıp alanında böyle bir çalışmanın yapılmamasının yanı sıra belirlenen bu temel yetkinlikler çevresinde farklı gruplardan elde edilen ölçek değerlerinin karşılaştırııması çalışmalarına rastlanmamıştır. Aynı zamanda daha nitelikli bir ölçek üzerinde uzmanlığını alan hekimlerin ve henüz mezun durumunda olmayan öğrencilerin yetkinliklere bakış açısının karşılaştırılması ve farklılıkların belirlenmesi önemli bulunmaktadır.

\section{Gereç ve Yöntem}

Bu çalışma. Tıp Fakültesi öğrencilerinin ve Uzman hekimlerin Uzman hekim yetkinliklerini ikili karşılaştırmalar yaparak ölçeklendiren. dolayısıyla var olan durumu olduğu biçimiyle betimlemeyi amaçlayan tarama modelinde betimsel bir çalışmadır. ${ }^{[18]}$

Çalışma Grubu: Bu çalışma; Hacettepe Üniversitesi 20132014 eğitim öğretim yılı güz döneminde; Tıp Fakültesinde görev yapmakta olan 34 uzman hekim ve Hacettepe Tıp fakültesinde öğrenim gören 47 Dönem IV öğrencisi ile yürütülmüştür. Çalışmanın yürütüldüğü grup çalışma ile ilgili bilgilendirilmiş olup çalışmaya katılımda gönülülük temel alınmıştır. Uzman hekimlerle karşılaştırılacak grubun Dönem IV seçilmesinin gerekçesi; çalışma grubuna alınan bu grubun preklinik eğitimi tamamlamış ve klinik eğitime başlamış olmasıdır. Klinik eğitime başlayarak hastane ortamına geçen öğrencilerin yetkinlikleri preklinik öğrencilerine göre daha doğru yorumlayacağı varsayılmıştır.

Veri Toplama Aracı: ikili karşılaştırmaların yapılacağı ACGME tarafından tanımlanan ve tüm dünyada kabul gören uzman hekim yetkinliklerinden oluşan bir ölçme aracı oluşturulmuştur (bkz. EK 1). Yetkinlikler ikili gruplar halinde eşleştirilmiş̧ir. Çalışma grubunun her bir ikili grupta verilen iki yetkinliğin bir tanesini mutlaka tercih etmeleri istenmiştir. Çalışma grubu her bir ikili gruptan tercih ettikleri bir yetkinliği işaretlemek üzere yönlendirilmiştir. Ölçme aracı altı yetkinliğe ait bütün ikili eşlemeleri içermektedir.

Veri Çözümleme Teknikleri: Bu araştırmada. Thurstone'un karşılaştırmalı yargı kanununa dayanan ve uyarıcıların. cevaplayıcılara ikişerli olarak verilebileceği her durumda kullanılabilen ikili karşılaştırmalar yoluyla ölçekleme tekniği ${ }^{[1]}$ kullanılmıştır. Bu teknikte. bir gözlemci. herhangi bir uyarıcıyı gözlediğinde uyarıcı tarafından gözlemciye. gözlemcinin kendisini ayırt etmesine esas teşkil edecek bir uyarıda bulunulduğu varsayılır. Gözlemci bu uyarıcıya göre. onu ayırt etme sürecinde bulunur ve bu süreç sonunda bir tepki gösterir. Bu tepki gözlemcinin. o uyarıcı hakkında bir ayırt etme yargısına vararak onu kendi algılamasına göre. bir nokta ile temsil etmesi veya bir değer vermesi şeklinde olur. Bu noktaların veya bunlara karşı gelen değerlerin (ayırt etme yargılarının) bulunduğu uzay ölçekleme boyutunu içeren bir uzaydır. Bir gözlemcinin. bir Uj uyarıcısının ölçekleme boyutundaki yeri- ni. her hangi bir ayırt etme süreciyle $\mathrm{N}$ defa belirlediğini; ya da N gözlemcinin bu gözlemi birer defa yapması halinde. tüm $\mathrm{N}$ gözlemcinin aynı yargıda birleşmesi değil. yargıların bir ortalama değer etrafında toplanması beklenir. Yukarıda verilen varsayım ve beklenti. ikili karşılaştırmalar yönteminin aşağıda verilen aksiyomlarını ortaya koyar.

Aksiyom 1: Bir gözlemciye uygulanan her uyarıcı. gözlemciye. bir ayırt etme süreci verir; gözlemci bu sürecin sonucunda uyarıcıyı. ölçekleme boyutunda bir nokta ile eşler.

Aksiyom 2: Organizmadaki anlık değişmeler sebebiyle gözlemci. bir uyarıcı tarafından her zaman aynı şekilde uyarılmayabilir veya gözlemci bu uyarıcıyı aynı şekilde algılamayabilir. Bu nedenle bir Uj uyarıcısına $\mathrm{N}$ gözlemci tarafından eşlenen noktalar birbirinden farklıdır. Bu noktaların ölçekleme boyutundaki dağııımı normaldir.

Aksiyom 3: Bu dağılımın ortalaması uyarıcının ölçek değeri ve standart kayması da ayırt etme dağılımının standart kaymasıdır.

Çalışmada uzman hekim yetkinliklerinin yer aldığı ölçme ara$\mathrm{Cl}$ ile hem uzman hekim hem de Dönem IV tıp fakültesi öğrencilerinden toplanan veriler için öncelikle ayrı ayrı frekans matrisleri oluşturulmuştur. Elde edilen Frekans matrislerinden yola çıkılarak oranlar matrisi oluşturulmuştur. Oranlar matrisinin her bir elemanına karşılık gelen z değerleri belirlenerek birim normal sapmalar matrisinin oluşturulmuştur. Birim normal sapmalar matrisinden yola çıkarak bu satırdaki her bir z değerinin ortalamaları hesaplanmış ve ölçek değerleri elde edilmiştir. Hem uzman hekimlerden hem de Dönem IV tıp fakültesi öğrencilerinden elde edilen ölçek değerleri sıralamaları karşılaştırılmıştır.

\section{Bulgular}

Hekimlerin ve Dönem IV öğrencilerinin her bir grupta diğerinden daha üstün olduğunu düşündükleri yetkinliği belirtmeleri istenmiştir. Hekimlere ve öğrencilere ait ölçekleme hesaplamaları ayrı ayrı elde edilmiştir.

Hekimlere ait bulgular: Hekimlere ait yargıların (sj>sk) frekansları Tablo1'deki gibi. 6 satır ve 6 sütunlu bir ham puanlar matrisinde (F matrisi) toplanmıştır. Frekanslar matrisi hesaplanmıştır (f matrisi) (bkz. Tablo 1). İkili karşılaştırmasında eşitlik durumu söz konusu olmadığı için köşegenin altında kalan frekansların bilinmesi hesaplamalar için yeterli olacaktır.

Tablo 2'de oluşturulan oranlar matrisinde matrisin köşegene göre simetrik olan (verilen ikiliden her birinin seçilme olasılıkları) elemanlarının toplamının bire eşit olduğu görülmektedir. Son olarak p oranlarına bağlı olarak birim normal dağılım fonksiyonunun z değerleri bulunmuştur (bkz. Tablo 3). Z matrisinin değerleri köşegene göre mutlak derece yönünden birbirine eşit olmak zorundadır.

Tablo 3'ten (Birim Normal Sapmalar Matrisi) yararlanılarak Tablo 4 'teki ölçek değerleri elde edilmiştir.

Tablo 4'te görüldüğü gibi Z değerlerinin en küçüğü Hasta ba- 
Tablo 1. Yetkinliklere ilişkin frekans matrisi

\begin{tabular}{|c|c|c|c|c|c|c|}
\hline & $\begin{array}{l}\text { Hasta } \\
\text { bakımı }\end{array}$ & $\begin{array}{l}\text { Tıbbi } \\
\text { bilgi }\end{array}$ & $\begin{array}{c}\text { Uygulamaya } \\
\text { dayalı } \\
\text { gelişim }\end{array}$ & $\begin{array}{l}\text { Öğrenme } \\
\text { ve iletişim } \\
\text { becerileri }\end{array}$ & Profesyonellik & $\begin{array}{c}\text { Sistemelere } \\
\text { dayalı } \\
\text { uygulama }\end{array}$ \\
\hline Hasta bakımı & - & 29 & 25 & 18 & 19 & 18 \\
\hline Tıbbi bilgi & 5 & - & 21 & 9 & 9 & 7 \\
\hline Uygulamaya dayalı öğrenme ve gelişim & 9 & 13 & - & 9 & 18 & 12 \\
\hline İletişim becerileri & 16 & 25 & 25 & - & 14 & 12 \\
\hline Profesyonellik & 15 & 25 & 16 & 20 & - & 12 \\
\hline Sistemelere dayalı uygulama & 16 & 27 & 22 & 22 & 22 & - \\
\hline
\end{tabular}

Tablo 1'deki F matrisinin her bir elemanı n=34'e bölünerek Tablo 2'deki P oranlar matrisi hesaplanmıştır.

Tablo 2. Yetkinliklere ilişkin oran matrisi

\begin{tabular}{lcccccc} 
& $\begin{array}{c}\text { Hasta } \\
\text { bakımı }\end{array}$ & $\begin{array}{c}\text { Tıbbi } \\
\text { bilgi }\end{array}$ & $\begin{array}{c}\text { Uygulamaya } \\
\text { dayalı } \\
\text { gelişim }\end{array}$ & $\begin{array}{c}\text { Ögrenme } \\
\text { ve iletişim } \\
\text { becerileri }\end{array}$ & $\begin{array}{c}\text { Profesyonellik } \\
\text { Sistemelere } \\
\text { dayalı } \\
\text { uygulama }\end{array}$ \\
\hline Hasta bakımı & - & 0.853 & 0.735 & 0.529 & 0.559 & 0.529 \\
Tıbbi bilgi & 0.147 & - & 0.618 & 0.265 & 0.265 \\
Uygulamaya dayalı öğrenme ve gelişim & 0.265 & 0.382 & - & 0.265 & 0.529 & 0.206 \\
Illetişim becerileri & 0.471 & 0.735 & 0.735 & - & 0.412 & - \\
Profesyonellik & 0.441 & 0.735 & 0.471 & 0.588 & 0.353 \\
Sistemelere dayalı uygulama & 0.471 & 0.794 & 0.647 & 0.647 & - & 0.647 \\
\hline
\end{tabular}

Tablo 3. Yetkinliklere ilişkin birim normal sapmalar matrisi

\begin{tabular}{|c|c|c|c|c|c|c|}
\hline & $\begin{array}{l}\text { Hasta } \\
\text { bakımı }\end{array}$ & $\begin{array}{l}\text { Tıbbi } \\
\text { bilgi }\end{array}$ & $\begin{array}{c}\text { Uygulamaya } \\
\text { dayalı } \\
\text { gelişim }\end{array}$ & $\begin{array}{l}\text { Öğrenme } \\
\text { ve iletişim } \\
\text { becerileri }\end{array}$ & Profesyonellik & $\begin{array}{c}\text { Sistemelere } \\
\text { dayalı } \\
\text { uygulama }\end{array}$ \\
\hline Hasta bakımı & - & 1.049 & 0.629 & 0.074 & 0.148 & 0.074 \\
\hline Tıbbi bilgi & -1.049 & - & 0.299 & -0.629 & -0.629 & -0.821 \\
\hline Uygulamaya dayalı öğrenme ve gelişim & -0.629 & -0.299 & - & -0.629 & 0.074 & -0.377 \\
\hline İletişim becerileri & -0.074 & 0.629 & 0.629 & - & -0.223 & -0.377 \\
\hline Profesyonellik & -0.148 & 0.629 & -0.074 & 0.223 & - & -0.377 \\
\hline Sistemelere dayalı uygulama & -0.074 & 0.821 & 0.377 & 0.377 & 0.377 & - \\
\hline
\end{tabular}

\section{Tablo 4. Ölçek değerlerinin gösterimi}

\begin{tabular}{lccc} 
& $\boldsymbol{\Sigma}$ zjk & Zjort. & Sj(ölçek değeri) \\
\hline Hasta bakımı & -1.974 & -0.329 & 0.000 \\
Tıbbi bilgi & 2.828 & 0.471 & 0.800 \\
Uygulamaya dayalı & & & \\
$\begin{array}{l}\text { öğrenme ve gelişim } \\
\text { İletişim becerileri }\end{array}$ & 1.861 & 0.310 & 0.639 \\
$\begin{array}{l}\text { Profesyonellik } \\
\text { Sistemelere dayalı }\end{array}$ & -0.584 & -0.097 & 0.232 \\
uygulama & -1.879 & -0.042 & 0.287 \\
\hline
\end{tabular}

kımına ait olan -1.974'dür. 0 noktası doğrusal dönüştürme ile yani bulunan en küçük değerin tüm uyarıcı değerlerine eklen- mesi ile sıfır noktasına kaydırılarak Sj değerleri bulunmuştur. Sj değerleri en küçükten büyüğe doğru sıralanarak ölçek değerleri Tablo 5'te verildiği şekilde elde edilmiştir.

Tablo 5'deki sonuçlar incelendiğinde hekim yetkinliklerinde 34 hekimin yargıları çerçevesinde ilk sıra Tıbbi Bilgiye (0.800). son sıra ise Hasta bakımına aittir. Hekimler bir hekimde bulunması gereken ilk niteliğin tıbbi bilgi olduğunu düşünmektedir. Dönem IV öğrencilerine ait bulgular: öğrencilere ait yargıların ( $\mathrm{sj}>\mathrm{sk}$ ) frekansları ham puanlar matrisinde ( $\mathrm{F}$ matrisi) toplanmıştır. Frekanslar matrisi hesaplanmıştır (f matrisi) (bkz. Tablo 6).

Tablo 6' deki $F$ matrisinin her bir elemanı $n=47$ 'ye bölünerek Tablo 7'deki P oranlar matrisi hesaplanmıştır.

Son olarak $p$ oranlarına bağlı olarak birim normal dağılım 
Tablo 5. Ölçek değerlerinin sıralı olarak gösterimi

\begin{tabular}{lcc} 
& Sj (ölçek değeri) & Yetkinliklerin ölçek değerlerine göre sıralaması \\
\hline Hasta bakımı & 0.000 & 1 \\
Sistemelere dayalı uygulama & 0.016 & 2 \\
İletişim becerileri & 0.232 & 3 \\
Profesyonellik & 0.287 & 4 \\
Uygulamaya dayalı öğrenme ve gelişim & 0.639 & 5 \\
Tıbbi bilgi & 0.800 & 6
\end{tabular}

Tablo 6. Yetkinliklere ilişkin frekans matrisi

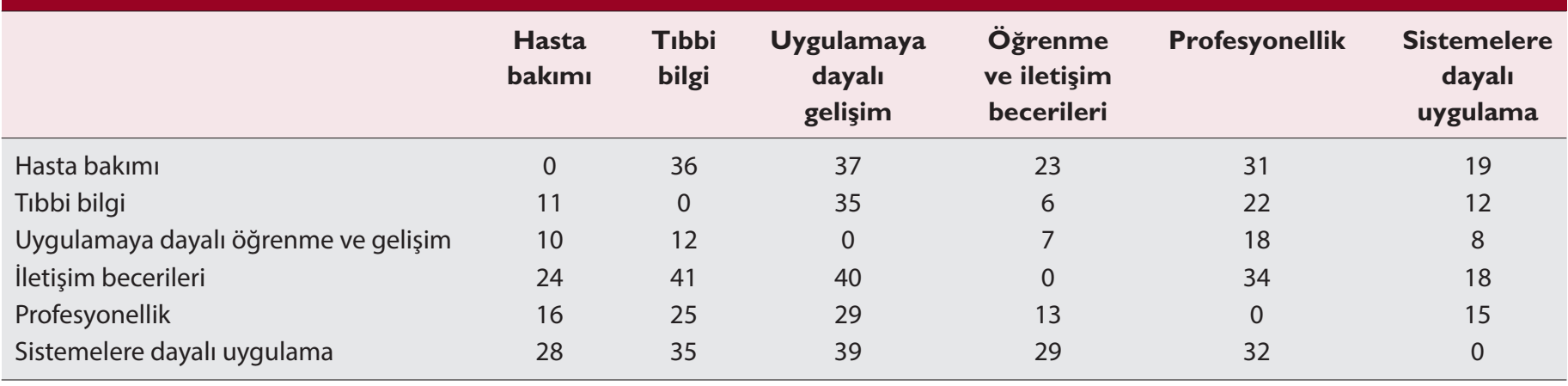

\section{Tablo 7. Yetkinliklere ilişkin oran matrisi}

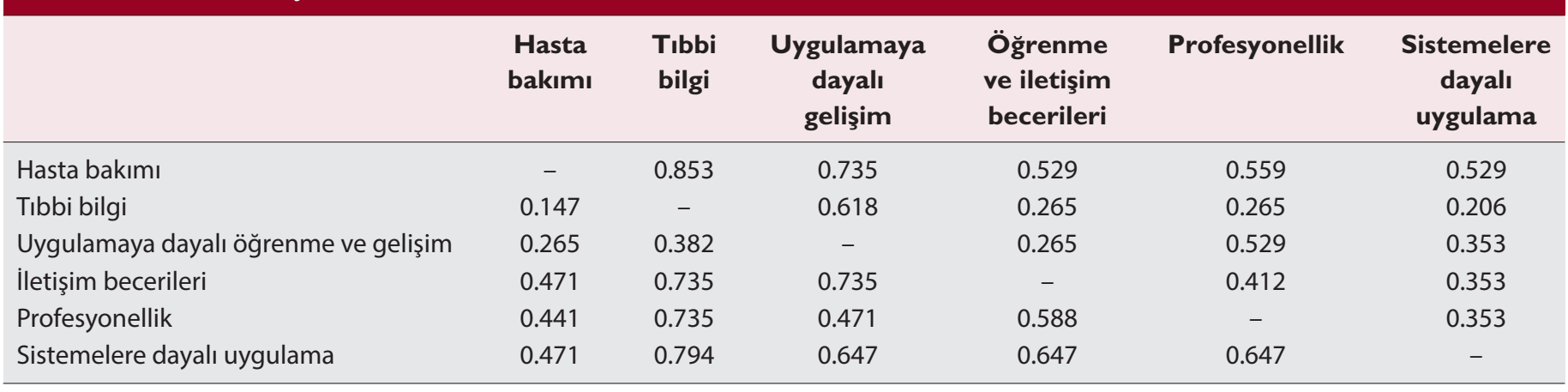

Tablo 8. Yetkinliklere ilişkin birim normal sapmalar matrisi

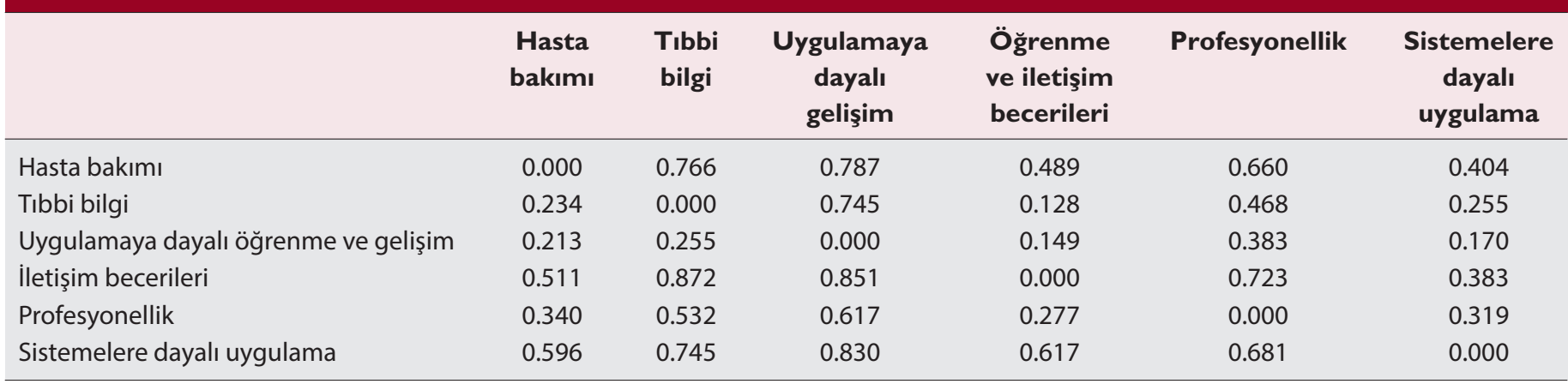

fonksiyonunun z değerleri bulunmuştur (bkz. Tablo 8). Z matrisinin değerleri köşegene göre mutlak derece yönünden birbirine eşit olmak zorundadır.

Tablo 8'deki Birim Normal Sapmalar Matrisinden yararlanılarak Tablo 9'daki ölçek değerleri elde edilmiştir.
Tablo 9'da görüldüğü gibi Z değerlerinin en küçüğü sistemelere dayalı uygulamaya ait olan -0.436 'dır. Bu değerin tüm uyarıcı değerlerine eklenmesi ile Sj değerleri bulunmuştur. Sj değerleri en küçükten büyüğe doğru sıralanarak ölçek değerleri Tablo 10'da verildiği şekilde elde edilmiştir. 
Tablo 9. Ölçek değerlerinin gösterimi

\begin{tabular}{lccc} 
& $\boldsymbol{\Sigma}$ zjk & Zjort. & Sj(ölçek değeri) \\
\hline Hasta bakımı & -1.664 & -0.277 & 0.159 \\
Tıbbi bilgi & 1.943 & 0.323 & 0.761 \\
Uygulamaya dayalı & & & \\
öğrenme ve gelişim & 3.747 & 0.624 & 1.061 \\
$\begin{array}{l}\text { Iletişim becerileri } \\
\text { Profesyonellik }\end{array}$ & -2.500 & -0.416 & 0.020 \\
Sistemelere dayalı & 1.096 & 0.182 & 0.620 \\
uygulama & -2.621 & -0.436 & 0 \\
\hline
\end{tabular}

Tablo 10. Ölçek değerlerinin sıralı olarak gösterimi

\begin{tabular}{lcc} 
& $\begin{array}{c}\text { Sj } \\
\text { (ölçek değeri) }\end{array}$ & $\begin{array}{c}\text { Yetkinliklerin ölçek } \\
\text { değerlerine göre } \\
\text { sıralaması }\end{array}$ \\
\hline Sistemelere dayalı & 0.000 & 1 \\
uygulama & 0.016 & 2 \\
İletişim becerileri & 0.232 & 3 \\
Hasta bakımı & 0.287 & 4 \\
Profesyonellik & 0.639 & 5 \\
Tıbbi bilgi & & 6 \\
Uygulamaya dayalı & 0.800 & 6 \\
öğrenme ve gelişim & 0.00 & \\
\hline
\end{tabular}

Tablo 10'daki sonuçlar incelendiğinde hekim yetkinliklerinde 47 dönem IV öğrencisinin yargıları çerçevesinde ilk sıra tıbbi bilgiye (0.800). son sıra ise hasta bakımına aittir. Klinik eğitime henüz geçen dönem IV öğrencileri bir hekimde bulunması gereken ilk niteliğin uygulamaya dayalı öğrenme ve gelişim olduğunu düşünmektedir.

Uzman hekim ve dönem IV öğrencilerinden elde edilen ölçek değerlerinin yetkinliklere göre sıralamasına ilişkin karşılaştırmalı Şekil 1'de yer almaktadır.

Uzman hekim ve dönem IV öğrencilerinden elde edilen ölçek

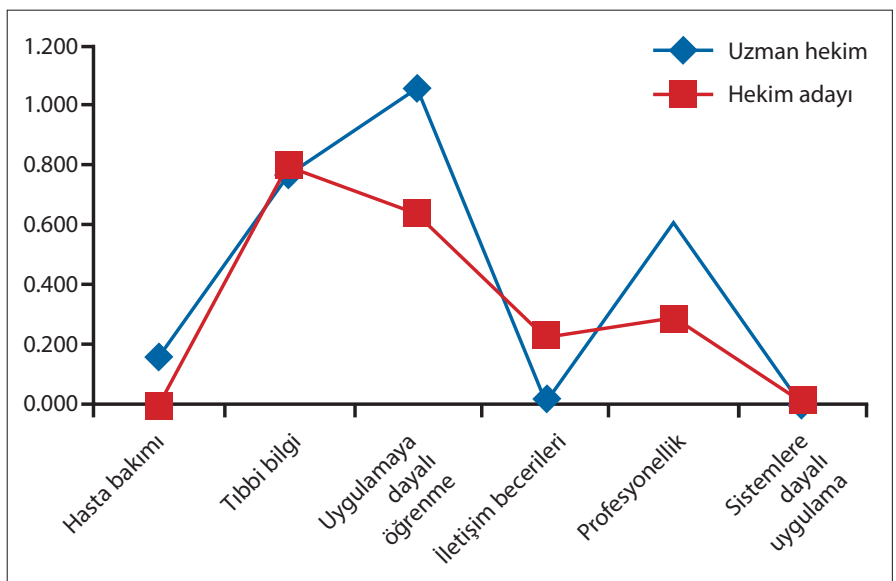

Şekil 1. Uzman hekim ve dönem IV öğrencilerinin ölçek değerlerinin yetkinliklere göre sıralaması değerlerinin karşılaştırmalı grafiği incelendiğinde tıbbi bilgi ve sistemlere dayalı uygulamaya ilişkin yargıların her iki grup içinde aynı büyüklükte fakat ölçek sıralamasında farklı yerlerde olduğu. diğer genel hekim yetkinlikleri için ise karşılaştırma yargılarının hem sıra hemde değer olarak birbirinden farklılaştığı görülmektedir. Hekimler tıbbi bilgiyi ölçek sıralamasında ikinci konuma yerleștirirken. öğrencilerden elde edilen ölçek değerleri sonucu tıbbi bilgi ilk sırada yeralmıştır. Öte yandan uzman hekimler uygulamaya dayalı öğrenmeyi ilk sırada belirlemişlerdir.

Ikili karşılaştırma ölçekleme yöntemlerinden elde edilen uzman hekim ölçek değerleri ve Dönem IV tıp fakültesi ölçek değerleri arasındaki tutarlıı̆ı belirlemek amacıyla Spearman-Brown sıra farkları korelasyon katsayısı hesaplanmıştır $(r=0.771 . p=0.07 . p>0.01)$. Uzman hekimlerin ve kliniğe geçiş yapan öğrencilerin yargıları arasında bir tutarlıık bulunmadığı bir başka ifade ile iki grubun yargılarına bağlı olarak oluşturulan ölçek değerlerinin birbirinden farklı olduğu sonucuna ulaşılmıştır.

\section{Tartışma}

Çalışmadan elde edilen bulgular göstermiştir ki; tüm dünya tarafından kabul gören uzman hekim yetkinliklerini sıralama biçimi uzman hekim ve hekim adayları açısından farklılaşmaktadır. Uzman hekimler için; en büyük değere sahip olan yetkinliğin tıbbi bakım becerisi. en küçük değere sahip olan yetkinliğin ise hasta bakımı iken; hekim adayları için ise; en büyük değere sahip olan yetkinliğin. en küçük değere sahip olan yetkinliğin ise sistemelere dayalı uygulama olduğu tespit edilmiştir. Elde edilen bu sonuç öğrenme ortamları. hekimlik mesleğine ilişkin geçirilen yaşantılar ve mesleksel tecrübe farklılığından kaynaklanabilir. Öğrenme ortamlarında henüz hekimlik yapmayan öğrenciler geçirmekte oldukları yaşantılar sebebi ile uygulamaya dayalı öğrenme ve gelişim olduğunu düşünebilmekte. gerçek uygulama koşullarında ise artık hekim söz konusu bu sürecin önüne sahip olduğu tıbbi bilgiyi yerleştirmektedir. Uzman hekim artık "Hizmet Sunucusu" olarak mevcut yaşantısını sosyal ortamda hastaya etkin bir biçimde aktarabilmek durumunda olup. ${ }^{[4]}$ en önemli ihtiyacının eğitimi boyunca edindiği. aynı zamanda gelişmelerle değişen gelişen dinamik tıbbi bilgi olduğunu. tıbbi bilginin klinik karar süreçlerini kolaylaştırdığını düşünüyor olabilir. Oysa hekim adayı henüz karar verici konumda değildir.

Bu farklılaşmanın diğer bir nedeninin de öğrencilerin beklentileri. meslek örgütlerinin beklentileri. toplumun beklentileri. ilgili iş ortamının gerektirdiklerinden kaynaklı olabileceği düşünülmektedir. Uzman hekim açısından bakıldığında; uzman hekimler formal ve informal ortamlarda bir biçimde yetkinlikleri kullanma durumunda kalmakta ve sahip oldukları yetkinliklerin sorumluluğunu almakla yükümlü bulunmaktadır. ${ }^{[19]}$ Dolayısıyla uzman hekim yetkinliklere ilişkin ölçeklemeyi yaparken mesleğini işe koştuğu hiçbir çevreden bağımsız gerçekleştiremez oysa hekim adayı henüz kendi beklentileri ve öğrenme ortamı dışında çevrelerin ve bu çevrelerin beklentilerinin yeterince farkında olamayabilir. 
Yetkinliklerden biri olan; "hasta bakımı” açısından yapılan ölçeklendirmeyi karşılaştırdığımızda; uzman hekimlerin bu yetkinliği son sıraya koyduğu; 4. sınıf klinik döneme geçiş yapan öğrencilerin ise bu yetkinliği 4. sıraya yerleştirmiş olması da geçirmekte oldukları mevcut yaşantı ve çevrenin hekimden ve hekim adayından beklentileri doğrultusunda açıklanabilir.

Nitel ayrımları gösteren gözlemlerden nicel ayrımlara geçişi sağlayan ölçekleme çalışmaları yetkinlikleri farklı bakış açıları ile ele almamızı kolaylaştırabilir. Bu ölçek değerleri nitel çalışmalar ile desteklenebilir. Daha nitelikli sonuçlar elde etmek için daha büyük bir grupta uygulanması yetkinliklerin ikili karşılaştırılması yapılabilir. Farklı eğitim ortamlarında eğitim görmüş uzman hekimler. farklı üniversitedeki hekim adayları. çeşitli sınıf düzeylerindeki tıp öğrencileri (klinik öncesi- klinik dönem). farklı uzmanlık alanlarına sahip hekimler. farklı bölgelerde ya da hastanelerde mesleğini yürüten hekimler... vs üzerinden karşılaştırma çalışmaları yürütülebilir. Farklı ölçekleme teknikleri ile yetkinlik sıralamalarına ilişkin ölçme ve değerlendirme. yanı sıra farklı yöntemlerden elde edilen ölçek değerlerine ilişkin karşılaştırma çalışmaları yapılabilir.

\section{Çıkar çatışması: Bildirilmemiştir.}

\section{Kaynaklar}

1. Akkaş E., Erdem R. Hekimlik Meslek Kültürünü Belirleyen Olguların Değerlendirilmesi. Süleyman Demirel Üniversitesi Vizyoner Dergisi 2017;8:47-57.

2. Rao. P.H. A Framework for Building Competency: Improving the Quality of Care at the Primary Health Level. ASCI Journal of Management 2010;39:68-94.

3. Dünya Tıp Eğitimi Federasyonu ve Avrupa Tıp Fakülteleri Birliği Uluslararası Çalışma Grubu ve Medine Niteliğin Sağlanması Çalışma Grubu DTEF. 2007 Copenhagen Üniversitesi Danimarka.

4. TUKMOS. Tıpta Uzmanlık Kurulu Müfredat Oluşturma ve Standart Belirleme Sistemi. Çekirdek Müfredat Hazırlama Kılavuzu. v.1.1. 2013.

5. Turgut M.F. ve Baykul. Y. Ölçekleme Teknikleri: Ankara: Ösym Yayınları. 1992.

6. Stevens. S. S. Handbook of experimental psychologhy. New York: John Willey and Sons. 1966.

7. Öğretmen T. Alan Tercih Envanteri: Ölçeklenmesi. Geçerliği Ve Güvenirliği. Türk Eğitim Bilimleri Dergisi 2008;6:507-22.

8. Brown. T. C. ve Peterson. G. L. An enquiry into the method of paired comparison: reliability. scaling. and Thurstone's law of comparative judgment. Gen Tech. Rep. RMRS-GTR-216WWW. Fort Collins. CO: U.S. Department of Agriculture. Forest Service. Rocky Mountain Research Station. 2009.

9. Titchener. E. B. Experimental psychology: a manual of laboratory practice. Volume1: Qualitative Experiments. New York: Macmillan. 1901.

10. Hays RB, Davies HA, Beard JD, Caldon LJ, Farmer EA, Finucane PM, et al. Selecting Performance Assessment Methods for Experienced Physicians. Papers from the 10th Cambridge Conference. Medical Education 2002;36:910-7.

11. Accreditation Council for Graduate Medical Education Report. http://www.acgme.org/

12. Anıl. D. Güler N. İkili Karşılaştırma Yöntemi İle Ölçekleme Çalışmasına Bir Örnek. H.Ü. Eğitim Fakültesi Dergisi (H.U. Journal Of Education) 2006;30.

13. Kan A. Yargıcı kararlarına dayalı ölçekleme yöntemlerinin karşılaştırılması üzerine ampirik bir çalışma. Hacettepe Üniversitesi Eğitim Fakültesi Dergisi 2008;35:186-94.

14. Albayrak. A. ve Gelbal. S. İkili karşılaştırmalar yargılarına ve sıralama yargılarına dayalı ölçekleme yaklaşımlarından elde edilen ölçek değerlerinin tutarlığının karşılaştırılması. 21. Ulusal Eğitim Bilimleri Kongresi. Marmara Üniversitesi Eğitim Fakültesi. 12-14 Eylül 2012. İstanbul.

15. Acar Güvendir M. ve Özer Özkan Y. İki ölçekleme yönteminin karşılaştırılması: İkili karşılaştırma ve sıralama yargıları. Eğitim Bilimleri Araştırmaları Dergisi - Journal of Educational Sciences Research 2015;3:105-19. http://ebad-jesr.com/

16. Ertoprak DG. Üniversite Tercihlerinde Etkili Olabilecek Özellikleri Belirlemeye Yönelik Bir Ölçekleme Çalışması. Amasya Üniversitesi Eğitim Fakültesi Dergisi 2015;4:153-74.

17. Özberk E.H. ve Ünsal Özberk E.B. Üstün yetenekli çocukları belirlemede öğretmen öncelikleri: İkili karşılaştırma yöntemiyle bir ölçekleme çalışması. Ankara Üniversitesi Eğitim Bilimleri Fakültesi Özel Eğitim Dergisi 2016;17:119-40.

18. Karasar. N. Bilimsel Araştırma Yöntemi. Ankara: Nobel Yayın Dağıtım Ltd. Şti. 2002.

19. Batalden $P$, Leach $D$, Swing S, Dreyfus H. Competency In GME. Health Affaırs 2002;21.

\section{EK- 1}

Uzmanlık alanından bağımsız olarak hekimden beklenen genel yetkinlikler;

- Hasta bakımı (Patient care)

- Tıbbi bilgi (Medical knowledge)

- Uygulamaya dayalı öğrenme ve gelişim (Practice-based learning and improvement)

- Kişiler arası iletişim becerileri (Interpersonal communication skills)

- Profesyonellik (Professionalism)

- Sistemlere dayalı uygulama (Systems-based practice)

olarak tanımlanmıştır (ACGME, 1990).

Bu çalışmada hekimden beklenen genel yetkinliklerin ikili karşılaştırma yolu ile ölçeklenmesi amaçlanmaktadır. Yetkinlikler açısından satır ve sütunlarda verilen her bir ikiliyi karşılaştırmanız ve size göre daha önemli olduğunu düşündüğünüz yetkinliğin numarasını kutucuğa yazmanız beklenmektedir. Katkılarınızdan dolayı teşekkür eder iyi çalışmalar dileriz.

\begin{tabular}{|c|c|c|c|c|c|}
\hline & 1. Hasta bakımı & & & & \\
\hline 2. Tibbi bilgi & & 2. Tibbibilgi & & & \\
\hline $\begin{array}{l}\text { 3. Uygulamaya } \\
\text { dayaliö̈renme } \\
\text { ve gelişim }\end{array}$ & & & $\begin{array}{l}\text { 3. Uygulamaya } \\
\text { dayalü̈̈rrenme } \\
\text { ve gelişim }\end{array}$ & & \\
\hline $\begin{array}{l}\text { 4. lletisisim } \\
\text { becerileri }\end{array}$ & & & & $\begin{array}{l}\text { 4. Illetisim } \\
\text { becerileri }\end{array}$ & \\
\hline 5. Profesyonellik & & & & & 5. Profesyonelli \\
\hline $\begin{array}{l}\text { 6. Sistemlere } \\
\text { dayalı uygulama }\end{array}$ & & & & & \\
\hline
\end{tabular}

